\title{
Actividad antimicrobiana, in vitro, del extracto etanólico de camu camu (Myrciaria dubia) contra microorganismos bucales
}

\author{
Karina Pardo Aldave', Maria Pareja Vásquez ${ }^{2}$, Bertha Jurado Teixeira ${ }^{3}$, \\ Alfredo Guillen Oneeglio ${ }^{4}$, Leopoldo Meneses Rivadeneira ${ }^{5}$, Ada Carolina Romero Coasaca $^{6}$
}

\section{Resumen}

Objetivo: Evaluar la actividad antimicrobiana, mediante el método de difusión en agar con pocillos, de camu camu (CC) contra microorganismos bucales. Métodos: Cepas de $S$. aureus, $S$. mutans, C. albicans y P. gingivalis fueron inoculadas en placas Petri. Extractos etanólicos (EEs) de cáscara, pulpa y semilla de CC y controles (clorhexidina $0,12 \%$, antiséptico bucal, alcohol $70^{\circ}$ y agua destilada) fueron cargados dentro de pocillos de $6 \mathrm{~mm}$ de diámetro. Todas las placas fueron incubadas por 24-48 horas y 11 días (P. gingivalis) a $35^{\circ} \mathrm{C}$ y la actividad antimicrobiana fue determinada por la formación de una zona de inhibición del crecimiento microbiano (ZICM), alrededor de los pocillos y medida mediante una regla Vernier, por un investigador, calibrado interexaminador. Se determinó el promedio de tres áreas diferentes de las ZICM (mm). El experimento fue ejecutado entre 3 y 14 réplicas. Se aplicó la estadística descriptiva e inferencial $(\mathrm{p}<0,05)$. Resultados: El EEs de semilla inhibió a los cuatro microorganismos. Por cada microorganismo, se evidenció diferencia significativa en la actividad antimicrobiana según grupo experimental $(p=0,0000)$ y entre pares de grupos $(p<0,001)$. Conclusión: Las tres partes de CC ejercieron, diferentes valores de actividad antimicrobiana contra microorganismos bucales, siendo similares o superiores a los antisépticos bucales.

Palabras clave: Myrtaceae, Streptococcus mutans, Staphylococcus aureus, Candida albicans, Porphyromonas gingivalis (fuente: DeCS BIREME).

\section{Abstract}

Objective: To evaluate the antimicrobial activity, through the agar diffusion method with wells, of camu camu (CC) against oral microorganisms. Methods: Strains of $S$. aureus, S. mutans, C. albicans and P. gingivalis were inoculated in Petri dishes. Ethanolic extracts (EEs) of peel, pulp and CC seed and controls $\left(0.12 \%\right.$ chlorhexidine, oral antiseptic, $70^{\circ}$ alcohol and distilled water) were loaded into $6 \mathrm{~mm}$ diameter wells. All plates were incubated for $24-48 \mathrm{~h}$ and 11 days $($ P. gingivalis $)$ at $35^{\circ} \mathrm{C}$ and the antimicrobial activity was determined by the formation of a zone of microbial growth inhibition (ZMGI), around the wells and measured by a Vernier caliper, by a researcher, calibrated interexaminer. The average of the different ZMGI areas (mm) was determined. The experiment was executed between 3 and 14 replicas. Descriptive and inferential statistics were applied ( $<<0.05)$. Results: Seed EEs inhibited the four microorganisms. For each microorganism, significant differentiation was observed in the antimicrobial activity according to experimental group $(\mathrm{p}=0.0000)$ and between pairs of groups $(\mathrm{p}<0.001)$. Conclusion: The three parts of CC exerted different values of antimicrobial activity against oral microorganisms, being similar or superior to oral antiseptics.

Keywords: Myrtaceae, Streptococcus mutans, Staphylococcus aureus, Candida albicans, Porphyromonas gingivalis (source: DeCS BIREME).

Introducción

La caries dental (CD) y periodontitis crónica (PC) son las enfermedades más prevalentes de la cavidad bucal ${ }^{(1)}$ y son inducidas por la biopelícula bucal ${ }^{(2)}$ (la que favorece la supervivencia de muchos microorganismos, como Staphylococcus). Además, son asociadas principalmente al Streptococcus mutans (S. mutans) $)^{(3)}$ y Porphyromonas gingivalis $(P \text {. gingivalis })^{(4)}$, respectivamente. Así mismo, la candidiasis es la infección micótica más común en el ser humano. La Candida albicans (C. albicans) es la especie del género Candida que prevalece con mayor frecuencia $(7,1 \%$ $26,9 \%$ ) en $\mathrm{PC}^{(5)}$. Actualmente, para el control de dichas enfermedades se recomienda realizar una buena higiene bucal. Sin embargo, el cepillado dental no es suficiente y se debe complementar con agentes antimicrobianos, siendo el más recomendado el gluconato de clorhexidina $(\mathrm{CHX})^{(6)}$. Lamentablemente, el uso de la CHX no debe prolongarse

${ }^{1}$ CD, Mag. Estomatología, Universidad de San Martín de Porres, Lima-Perú. ${ }^{2}$ CD, Doctor en Educación, Facultad de Odontología, Universidad de San Martín de Porres, Lima-Perú. ${ }^{3}$ QF, Facultad de Farmacia, Universidad Nacional Mayor de San Marcos, Lima-Perú.

${ }^{4}$ MC, Facultad de Tecnología Médica, Universidad Nacional Federico Villarreal, Lima-Perú. ${ }^{5}$ CD, Esp. CBMF, Facultad de Estomatología, Universidad Peruana Cayetano Heredia, Lima-Perú. ${ }^{6}$ CD. Facultad de Odontología, Universidad de San Martín de Porres, Lima-Perú. 
pasados los 15 días, ya que puede presentar efectos adversos como: tinción de los dientes, cambio en el sabor e incremento del tártaro supragingival ${ }^{(7)}$. Por lo tanto, continúa la búsqueda de un agente con eficacia antimicrobiana y que no presente efectos adversos, siendo las plantas y frutos importantes fuentes de principios activos con propiedades medicinales y sin los efectos adversos mencionados anteriormente.

Los frutos de Myrciaria dubia, comúnmente conocidos como camu camu (CC), son cultivados en la Amazonía Peruana y Brasileña ${ }^{(8)}$. Con propiedades antioxidantes ${ }^{(9)}$, antimicrobianas ${ }^{(10-14)} /$ antiinfecciosas ${ }^{(15)}$, además de antihipertensiva, antihiperglicemia ${ }^{(16)}$ y contra la diabetes tipo 2 y sus complicaciones ${ }^{(15)}$, son grandes aliados contra enfermedades cardiovasculares y obesidad $^{(17)}$, así mismo, sus hojas contienen componentes antiplasmódicos y leishmanicidas ${ }^{(18)}$, etc. Tales propiedades son atribuidas a los compuestos bioactivos que presenta, como el ácido ascórbico ${ }^{(19)}$, polifenoles ${ }^{(16)}$, flavonoides ${ }^{(15)}$, taninos, carotenoides ${ }^{(20)}$, fenoles, etc. De acuerdo a investigaciones previas, la concentración de dichos componentes varía según la parte del fruto, por ejemplo, se ha hallado mayor cantidad de compuestos fenólicos (incluyendo polifenoles) y capacidad antioxidante en la pulpa que en la cáscara $^{(21)}$, mientras que en la cáscara se han encontrado los compuestos myrciarone A y rhodomyrtone ${ }^{(22)}$ y en la semilla los compuestos isomyrtucommulone $\mathrm{B}$ y myrciarone $\mathrm{B}$, todos ellos exhibieron actividades antimicrobianas ${ }^{(23)}$.

De igual manera, la propiedad antimicrobiana de los frutos de CC ha sido atribuida a su cáscara, pulpa y semilla. Se evidenció que, los extractos hidroalcohólicos de semilla ${ }^{(11,24)}$, pulpa $^{(15)}$, cáscara $^{(11,25)}$, hojas y corteza ${ }^{(12)}$, los extractos n-hexano de cáscara ${ }^{(22,23)}$ y semilla ${ }^{(23)}$, el extracto acuoso de pulpa ${ }^{(15)}$ y extracto etanólico de cáscara ${ }^{(13)}$ evidenciaron actividad antimicrobiana contra $S$. aureus. Del mismo modo, los extractos hidroalcohólicos de hojas ${ }^{(25)}$, extractos metanólico de semilla y pulpa ${ }^{(26)}$ y el extracto etanólico de cáscara ${ }^{(27)}$ inhibieron el crecimiento de $S$. mutans. Finalmente, el extracto etanólico de cáscara de $M$. dubia mostró actividad antimicrobiana contra C. albicans ${ }^{(13)}$ y el zumo al $100 \%$ de $M$. dubia inhibió el crecimiento de Escherichia coli y Salmonella typhi $i^{\text {(28). }}$

De comprobarse la actividad antimicrobiana de los extractos etanólicos (EEs) de cáscara, pulpa y semilla de CC, nos permitiría conocer la parte del fruto que ejerce mayor y/o menor inhibición del crecimiento de los principales microorganismos asociados a CD, PC y candidiasis. Además, representarían una opción económica, efectiva y sin los efectos adversos de los fármacos convencionales, para las personas que optan por alternativas naturales.

Por lo tanto, la presente investigación evaluó la actividad antimicrobiana, in vitro, de los EEs de semilla, cáscara y pulpa de camu camu sobre cultivos de $S$. mutans (ATCC 25175), S. aureus (ATCC 25923), C. albicans (ATCC 10231) y P. gingivalis (ATCC 33277).

\section{Métodos}

Estudio experimental, in vitro, cuyo proyecto fue aprobado por el Comité de Ética e Investigación de la Facultad de Odontología de la Universidad de San Martín de Porres (acta $\mathrm{N}^{\circ} .24$ - 09 junio de 2015).

\section{Estudio piloto}

Se realizó con el objetivo de calibrar al investigador principal (KPA) en la medición de la zona de inhibición del crecimiento microbiano y determinar el tamaño mínimo de grupos experimentales (TMGE), por microorganismo.

Para evaluar la confiabilidad interexaminador, tanto el investigador principal (KPA) como el estándar de oro (AG), de manera independiente, registraron tres áreas diferentes (en $\mathrm{mm}$ ) de 20 zonas de inhibición, usando una regla Vernier. Luego, se obtuvo el promedio de dichas tres áreas y mediante el estadístico Coeficiente de Correlación de Intraclase (CCI) se obtuvo una concordancia de muy bueno $(\mathrm{p}=0,9904)$.

Para establecer los TMGEs, se halló la diferencia mínima entre grupos experimentales y se aplicó la prueba para comparar dos medias independientes, en el paquete estadístico Stata v. 014, considerando un nivel de potencia del $80 \%$ y un error del tipo I del 5\% (una cola). Al comparar los tres EEs de $\mathrm{CC}$ versus controles, en cada microorganismo, se obtuvo que el TMGE estuvo entre 2 y 3 réplicas. Excepto para $S$. mutans que, al contrastar el EE de semilla versus CHX al 0,12\% y un antiséptico bucal determinó 7 y 4 réplicas, respectivamente. Asimismo, fue para $S$. aureus que, al comparar el mismo EE contra $\mathrm{CHX}$ al $0,12 \%$ se obtuvo 14 réplicas.

\section{Obtención de los extractos etanólicos (EES) de camu camu (CC)}

Los frutos de CC fueron obtenidos a través del biólogo (JCDC). En el laboratorio de Farmacognosia y Medicina Tradicional de la Facultad de Farmacia de la Universidad Nacional Mayor de San Marcos (UNMSM) y bajo la supervisión de la Dra. Bertha Jurado Texeira, se separaron la cáscara, pulpa y semilla. Luego, se secaron a temperatura ambiente y una vez secas, fueron molidas; cada uno de los polvos de las muestras se colocaron en matraces de vidrio, color ámbar y se le adicionó etanol para su maceración, los tres matraces fueron cerrados herméticamente con parafilm, su maceración fue a temperatura ambiente y se llevaron a un cuarto oscuro, por siete días. Luego, se realizó un filtrado con papel filtro $\mathrm{N}^{\circ} 40$ y los extractos obtenidos se llevaron al rotavapor para su concentración. Los EEs fueron pesados y colocados en botellas de color ámbar y mantenidas bajo refrigeración hasta su uso.

\section{Cepas de microorganismos estudiados}

Cuatro cepas de microorganismos (gram positivos: $S$. mutans (ATCC 25175), S. aureus (ATCC 25923) y C. albicans (ATCC 10231) y un gram negativo: P. gingivalis (ATCC 33277)) fueron obtenidos del Laboratorio GenLab del Perú S.A.C; Perú.

\section{Actividad antimicrobiana}

Los EEs de CC fueron estudiados para la sensibilidad de los cuatro microorganismos, mediante el método de difusión 
en agar con pocillo ${ }^{(29)}$. Cada microorganismo fue inoculado en placas Petri con agar Mueller-Hinton, agar Mueller Hinton sangre, agar Mueller Hinton dextrosa azul de metileno y agar Brucella suplementado con sangre de cordero al 5\% con vitamina $\mathrm{K}$ y hemina, respectivamente. Los EEs fueron cargados dentro de pocillos de $6 \mathrm{~mm}$ de diámetro. Pocillos control fueron cargados con clorhexidina (CHX) al $0,12 \%$, antiséptico bucal LISTERINE ${ }^{\mathbb{B}}$ CUIDADO TOTAL ZERO ${ }^{\mathrm{TM}}$ (contiene cuatro aceites esenciales (timol, eucaliptol, mentol y salicilato de metilo, cloruro de zinc y flúor de Johnson \& Johnson, USA), alcohol etanol de $70^{\circ}$ y agua destilada. Todas las placas fueron incubadas por $24-48 \mathrm{~h} \mathrm{u} 11$ días a $37^{\circ} \mathrm{C} \mathrm{o}$ $35^{\circ} \mathrm{C}$ y la actividad antimicrobiana fue determinada por la formación de una zona de inhibición del crecimiento microbiano (ZICM) alrededor de los pocillos y medida mediante una regla Vernier, por un investigador, calibrado interexaminador (CCI, $\mathrm{p}=0,9904)$. Se determinó la media de tres áreas diferentes de las ZICM en mm e incluyó el diámetro del pocillo y no mostró obvio ni visible crecimiento, juzgado a simple vista. En caso de resistencia microbiana (no existe ZICM), simplemente se midió el diámetro del pocillo (6 $\mathrm{mm})^{(30)}$. El experimento fue replicado según los TMGEs obtenidos en el estudio piloto.

Los datos se analizaron empleando el paquete estadístico Stata v. 14.0 para Windows Corporation (Stata, Texas, EE.UU.). Por cada microorganismo, la actividad antimicrobiana (AA) se describió en medias y desviaciones estándar. Luego, se aplicó ANOVA de una sola vía para establecer la variabilidad, en conjunto, de la AA en función al grupo experimental. Y para comparar la AA de los EEs entre sí y versus controles positivos y negativo, se aplicó Scheffe, debido al cumplimiento de los supuestos de normalidad (Prueba Shapiro Wilk, $\mathrm{p} \geq 0,10011)$ y homogeneidad de varianza (Prueba Bartlett, $\mathrm{p} \geq 0,892$ ).

\section{Resultados}

Las medias y desviaciones estándar de las ZICM, según grupo experimental, se presentan en la tabla 1.
El extracto etanólico (EE) de semilla inhibió el crecimiento de los cuatro microorganismos y fue el único que inhibió a la C. albicans (Tabla 1; Figuras 1 y 2).

Se evidenció diferencia significativa entre el EE de pulpa versus la cáscara y semilla sobre $S$. mutans $(\mathrm{p}<0,001)$ y $P$. gingivalis $(\mathrm{p}<0,001)$, respectivamente. Así mismo, fue para el EE de semilla contra cáscara y pulpa ante $S$. aureus $(\mathrm{p}<0,001)$ y C. albicans $(\mathrm{p}<0,001)$, respectivamente. No se halló diferencia significativa entre los tres EEs de CC y la CHX al 0,12\% para $S$. mutans ( $\mathrm{p} \geq 0,100)$, excepto para el EE de semilla $(\mathrm{p}=0,003)$. También, hubo diferencia significativa al contrastar los tres EEs con CHX al $0,12 \%$ sobre $S$. aureus $(\mathrm{p} \geq 0,002)$ y entre los tres EEs comparados con antiséptico bucal $(\overline{\mathrm{AB}})$ y alcohol a $70^{\circ}$ para $S$. mutans, $S$. aureus y $C$. albicans $(\mathrm{p} \leq 0,043)$, respectivamente, excepto para los EEs de cáscara y pulpa contra el alcohol a $70^{\circ}$ sobre la $C$. albicans ( $\mathrm{p}=1,000$, respectivamente). Finalmente, para $P$. gingivalis hubo diferencia significativa entre los tres EEs comparados con alcohol a $70^{\circ}(p<0,001)$ y el EE de pulpa versus el AB ( $p<0,001)$ (Tabla 1$)$.

\section{Discusión}

En la presente investigación, se evaluó in vitro la inhibición de $S$. mutans, $S$. aureus, $C$. albicans y $P$. gingivalis ante tres extractos etanólicos (EEs) de cáscara, pulpa y semilla de CC, comparados con CHX al 0,12\%, antiséptico bucal, alcohol a $70^{\circ}$ y agua destilada.

Se encontró que los tres EEs de CC inhibieron el crecimiento de $S$. aureus, lo cual concuerda con Myoda y col. ${ }^{(11)}$ (2010), Fujita y col. $\left(2013^{(14)}\right.$ y $2015^{(15)}$ ) y Kaneshima y col. $\left(2015^{(22)}\right.$ y $\left.2017^{(23)}\right)$, quienes estudiaron a los extractos hidroacetónicos de semilla y cáscara ${ }^{(11)}$, extractos hidroalcohólico de pulpa congelada (secada por dos procesos de deshidratación) ${ }^{(14)}$. Así también, extractos acuosos de pulpa, congelada (provenientes de la amazonia de Brasil y Sao Paulo y secadas por liofilización y aspersión ${ }^{(15)}$. Y por último, extractos hexánicos de cáscara ${ }^{(22,23)}$ y semilla ${ }^{(23)}$ de CC, respectivamente, los que mostraron actividad ante $S$. aureus.

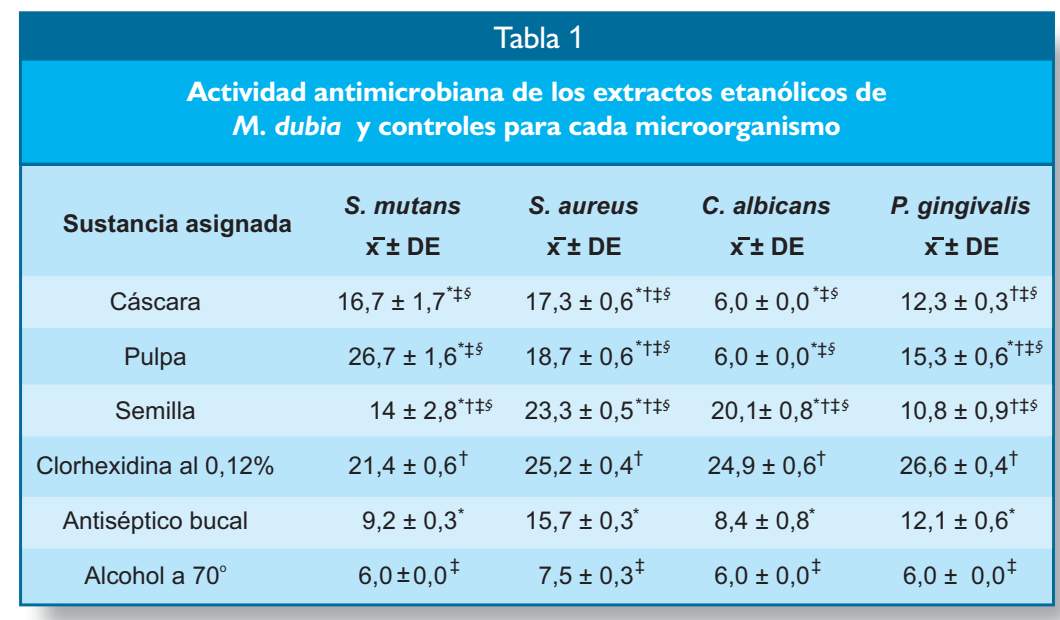

$x=$ media aritmética; $D E$ = desviación estándar; ${ }^{*}+\ddagger \S$ = diferencia significativa $($ Scheffe, $p<0,05) ; n=3-15$ réplicas; agua destilada no mostró zona de inhibición $(6 \mathrm{~mm})$. 


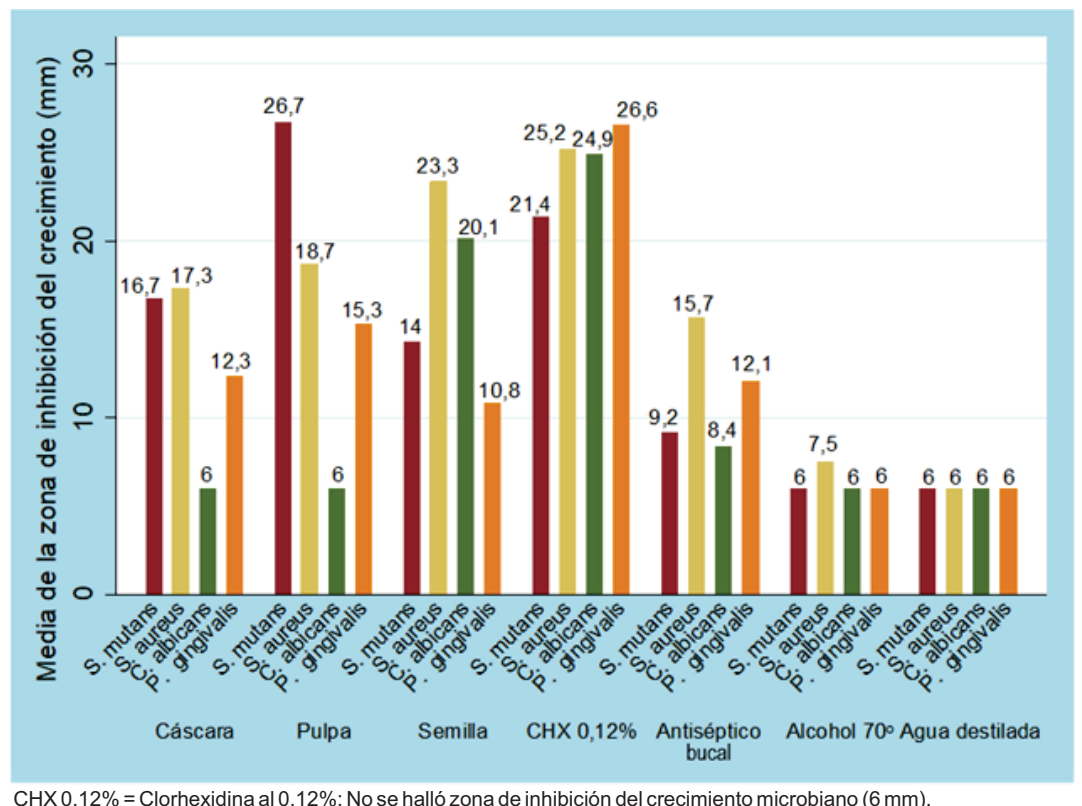

Figura 1. Evaluación, in vitro, de la actividad antimicrobiana de tres extractos etanólicos de $M$. dubia sobre cepas de S. mutans, S. aureus, C. albicans y P. gingivalis.

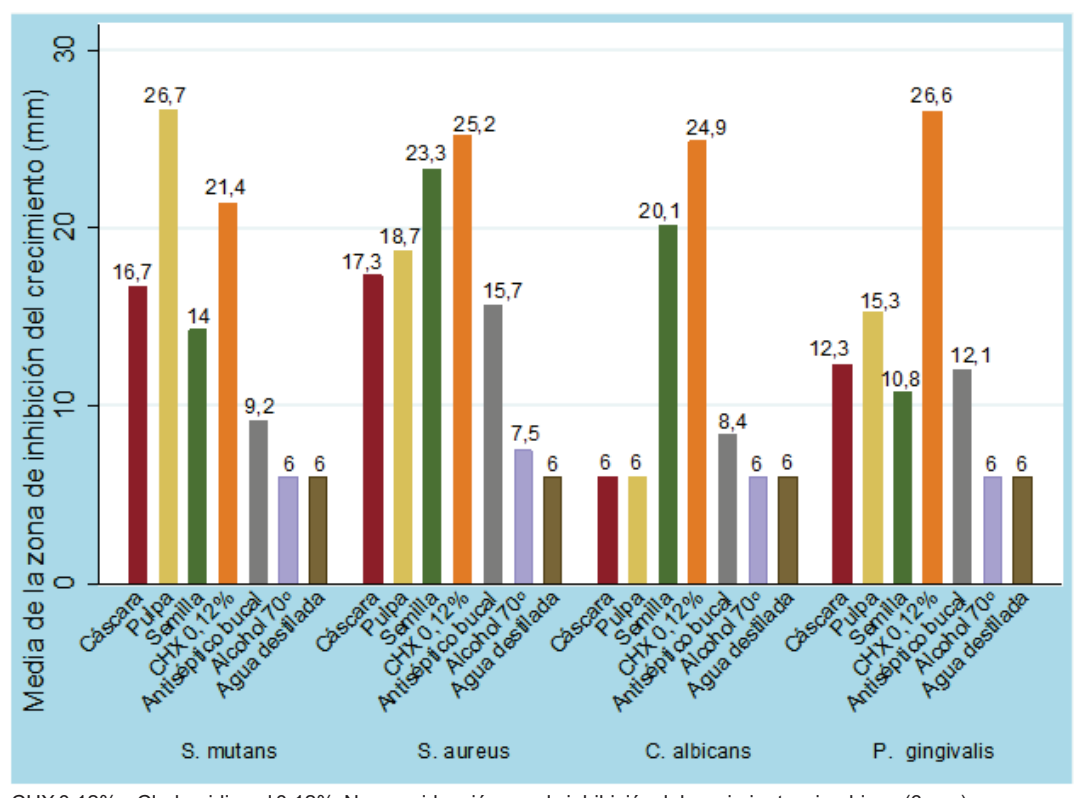

$\mathrm{CHX} 0,12 \%$ = Clorhexidina al $0,12 \%$; No se evidenció zona de inhibición del crecimiento microbiano (6 mm).

Figura 2. Inhibición del crecimiento microbiano mediante extractos etanólicos de M. dubia y controles.

Del mismo modo, los EEs en estudio inhibieron a $S$. mutans y coincide con Camere-Colarossi y col. ${ }^{(26)}$ en el 2016, Saldarriaga-Mostacero y col. ${ }^{(27)}$ (2017), Castillo-Carranza y col. $^{(13)}$ (2013) y Kaneshima y col. en los años $2015^{(22)}$ y $2017^{(23)}$, en los cuales extractos de CC inhibieron el crecimiento de $S$. mutans. Tales como, extractos metanólicos de semilla y pulpa, liofilizadas ${ }^{(26)}$, cuatro fracciones del extracto etanólico de la cáscara de $\mathrm{CC}^{(13,27)}$. Y finalmente, extractos hexánicos de cáscara $^{(22,23)}$ y semilla ${ }^{(23)}$, y biocomponentes aislados, respectivamente.
Así también, se evidenció que $C$. albicans solo fue sensible ante el EE de semilla, lo cual no se corresponde con Castillo-Carranza y col. ${ }^{(13)}$ (2013), en donde cuatro fracciones del EE de cáscara inhibieron a dicho microorganismo.

Por otra parte, se obtuvo que la actividad antimicrobiana del EE de semilla de CC fue mayor que la cáscara y pulpa sobre $S$. aureus, lo cual se relaciona y no con Kaneshima y col. $^{(23)}$ (2017) y Myoda y col. ${ }^{(11)}$ (2010), respectivamente. En el primero, tres extractos hexánicos de semilla fueron mejor que 
la cáscara ${ }^{(23)}$. Y en el segundo un extracto hidroalcohólico de cáscara fue más fuerte que la semilla $(5,0 \mathrm{mg} / \mathrm{mL}$ de concentración) $)^{(11)}$.

Así mismo, se halló que la actividad antimicrobiana del EE de pulpa contra $S$. mutans fue mayor que la cáscara y semilla; además se evidenció que estos dos extractos ejercieron actividades similares contra dicha bacteria. Lo cual coincide y no con Kaneshima y col. ${ }^{(23)}$ (2017) y Camere-Colarossi y col. ${ }^{(26)}$ (2016), respectivamente. En el primero, dos extractos hexánicos de cáscara y semilla de CC obtuvieron efectos similares entre si sobre $S$. mutans ${ }^{(23)}$. Y el segundo mostró que el extracto metanólico de semilla fue mayor que la pulpa frente a dicho microorganismo ${ }^{(26)}$.

Nuestra investigación demostró que al comparar las actividades antimicrobianas de EEs de semilla y pulpa de CC versus CHX al $0,12 \%$ sobre $S$. mutans, estos fueron menor y similar, respectivamente, lo cual se corresponde y no con Camere-Colarossi y col. ${ }^{(26)}$ (2016), donde el efecto de extractos metanólicos de semilla y pulpa fueron menores que la $\mathrm{CHX}$ al $0,12 \%$.

En el presente estudio, in vitro, para $S$. mutans no se encontró diferencia significativa entre los EEs de cáscara y pulpa de CC comparado con CHX al $0,12 \%$ ( $p=0,195$ y $\mathrm{p}=0,100$, respectivamente). Así mismo, fue al contrastar los tres EEs con el antiséptico bucal frente $S$. mutans y $S$. aureus. Y también para el EE de pulpa sobre $P$. gingivalis. Además, al comparar los EEs de pulpa contra la cáscara y semilla ante $\mathrm{S}$. mutans y P. gingivalis se demostró mejores resultados con la pulpa $(\mathrm{p}<0,001$, respectivamente). Y al contrastar el EE de semilla versus pulpa y cáscara sobre $S$. aureus y $C$. albicans, el de semilla tuvo mayor actividad ( $<<0,001$, respectivamente). Lo cual sugiere que la propiedad de inhibir el crecimiento microbiano puede variar en función a la parte del fruto de CC utilizada. Sin embargo, más estudios al respecto son requeridos para determinar la relación parte CC/actividad antimicrobiana.

Cabe resaltar que, esta investigación es la primera que compara los EEs de cáscara, pulpa y semilla entre sí, contra el antiséptico bucal, sobre $P$. gingivalis y contrasta el extracto de cáscara versus CHX, para demostrar la actividad antimicrobiana del CC sobre microorganismos relacionados a $\mathrm{CD}, \mathrm{EP}$ y candidiasis y por ende, más relevantes de la cavidad bucal; la gran mayoría de investigaciones, realizadas hasta el momento, han estudiado solo una o dos partes del fruto de $\mathrm{CC} \mathrm{y}$ comparan sus actividades contra antibióticos y antifúngicos (principalmente) y solo dos estudios contrastaron pulpa, semilla y hojas versus $\mathrm{CHX}$, respectivamente.

\section{Conclusión}

El EE de semilla de CC inhibió el crecimiento de los cuatro microorganismos estudiados. Por otra parte, el $S$. mutans y $P$. gingivalis fueron más sensibles ante el EE de pulpa, mientras que el $S$. aureus y $C$. albicans lo fueron frente al de semilla. Además, la actividad antimicrobiana de los tres EEs de CC sobre los cuatro microorganismos fueron menores a la CHX al 0,12\%. Excepto, para el $S$. mutans en donde la actividad de los EEs de cáscara y pulpa, fueron similares a la $\mathrm{CHX}$ al 0,12\%. Finalmente, los tres EEs evidenciaron mayor actividad antimicrobiana comparados con el antiséptico bucal (AB) y alcohol a $70^{\circ}$ frente a $S$. mutans y $S$ aureus. De igual forma, la $C$. albicans solo fue sensible ante el EE de semilla, siendo su inhibición mayor que el AB y alcohol a $70^{\circ}$. Por último, los tres EEs ejercieron mayor inhibición de $P$. gingivalis que el alcohol a $70^{\circ}$ y la actividad del EE de pulpa fue similar al AB sobre dicha bacteria. Estos hallazgos podrían significar una alternativa, natural, para inhibir el crecimiento de microorganismos, considerados entre los más importantes agentes etiológicos de la CD, EP y candidiasis, siendo similares o superiores a antisépticos bucales. Se sugiere una profunda investigación de la actividad antimicrobiana de los tres EEs de camu camu.

\section{Agradecimientos}

Esta propuesta de investigación recibió la subvención de la Fundación Instituto Hipólito Unanue (FIHU), mediante su programa "Aporte a la Investigación Científica 2016", para su ejecución.

\section{Referencias bibliográficas}

1.Gómez-Arcila V, Verbel-Bohorquez J, Díaz-Caballero A, Arroyo-Salgado B. Enfoque hacia la dinámica de la biopelícula oral para el control de enfermedades bucales prevalentes. Rev Clin Med Fam. 2014;7(2):153-155.

2.American Academy of Periodontology. The pathogenesis of periodontal diseases. J Periodontal. 1999;70(4):457-470.

3.Ojeda-Garcés JC, Oviedo-García E, Salas LA. Streptococcus mutans y caries dental. Rev CES Odont. 2013;26(1):44-56.

4.Derradjia A, Alanazi H, Park HJ, Djeribi R, Semlali A, Rouabhia M. $\alpha$-tocopherol decreases interleukin- $1 \beta$ and 6 and increases human $\beta$--defensin-1 and -2 secretion in human gingival fibroblasts stimulated with Prophyromonas gingivalis lipopolysaccharide. J Periodontal Res. 2016;51(3):295-303.

5.Ardila-Medina CM, Alzate-Vega J, Guzman-Zuluaga
IC. Eficacia in vitro de la moxifloxacina frente a Candida albicans en enfermedad periodontal. Av Periodoncia. 2014;26(1):45-50.

6. Barrón-González MP, Quiñones-Gutiérrez Y. Actividad bactericida de Castela texana sobre bacterias relacionadas a caries dental y gingivitis. RICS. 2013;2(4):1-24.

7. Gaete-Forno MJ, Oliva-Mella P. Efectividad del colutorio de manzanilla comparado con placebo y clorhexidina en pacientes con gingivitis entre los 19 y 25 años: Ensayo Clínico Controlado. Int J Odontostomat. 2012;6(2):151-156.

8. Correa-Meléndez FM, Cobos-Ruiz M, Ramírez-Saavedra R, Imán-Correa SA, Castro-Gómez JC. Fluctuación diurna del contenido de vitamina C en hojas de M. dubia "camu-camu". Cienc Amaz (Iquitos). 2013;3(2):60-66

9. Vasconcelos-Costa AG, García-Diaz DF, Jimenez P, Ibrahim-Silva P. Bioactive compounds and health benefits of 
exotic tropical red-black berries. J Funct Foods. 2013;5(2):539549.

10. Pacci-Salazar K, Nureña-Noriega L, Vásquez-Cerro J, Araujo-Espinoza G, Gálvez-Niño M. Eficacia tópica de Myrciaria dubia en la curación de quemaduras de segundo grado en ratas Holtzman. CIMEL. 2009;14(1):15-20.

11. Myoda T, Fujimura S, Park B, Nagashima T, Nakagawa J, Nishizawa M. Antioxidative and antimicrobial of residues de camu-camu juice production. J Food Agri Environ. 2010;8(2):304-307.

12. Mori T, Ruiz E, García M, Bardales J, Tresierra Á, Bendayán M. et al. Efecto antimicrobiano de Myrciaria dubia (camu-camu) y Cyperus luzulae (piri piri) sobre microorganismos patógenos. Conoc Amaz. 2016;4(1):49-57.

13. Castillo-Carranza CN, Mejía-Delgado EM. Efecto inhibitorio in vitro de Myrciaria dubia "camu-camu" sobre $S$. aureus y C. albicans [Tesis Bachiller en medicina]. Trujillo: Universidad Nacional de Trujillo; 2013.

14. Fujita A, Borges K, Correia R, Gombossy de Melo Franco BD, Genovese MI. Impact of spouted bed drying on bioactive compounds, antimicrobial and antioxidant activities of commercial frozen pulp of camu-camu (Myrciaria dubia Mc. Vaugh). Food Res Int. 2013;54:495-500.

15. Fujita A, Sarkar D, Wu S, Kennelly E, Shetty K, Genovese MI. Evaluation of phenolic-linked bioactives of camu-camu (Myrciaria dubia) for antihyperglycemia, antihypertension, antimicrobial properties and cellular rejuvenation. Food Res Int. 2015;77:194-203.

16. Fujita A, Sarkar D, Genovese MI, Shetty K. Improving antihyperglycemic and anti-hypertensive bioactive properties of camu-camu (Myriciaria dubia Mc. Vaugh) using lactic acid bacterial fermentation. Process Biochem. 2017;59:133-140.

17. Arellano-Acuña E, Rojas-Zavaleta I, Paucar-Menacho LM. Camu-camu (Myrciaria dubia): Fruta tropical de excelentes propiedades funcionales que ayudan a mejorar la calidad de vida. Sci Agropecu [Internet]. 2016 [Consultado: 03 Octubre 2018];7(4):[1 página]. Disponible en: http://dx.doi.org/10.17268/sci.agropecu.2016.04.08

18. Correia VCDS, Lima NO, Oliveira FADS, Santos APDAD, Teles CBG, Oliveira Júnior WPD, et al. Evaluation of the antiplasmodial and leishmanicidal potential of Myrciaria dubia (Myrtaceae) extract. Rev Soc Bras Med Trop. 2016 Oct;49(5):[1 página].

19. Castro JC, Maddox JD, Cobos M, Requena D, Zimic M, Bombarely A, et al. De novo assembly and functional annotation of Myrciaria dubia fruit transcriptome reveals multiple metabolic pathways for L-ascorbic acid biosynthesis. BMC Genomics. 2015;16:997.

20. Aguiar JPL, do Amaral Souza, FDC. Antioxidants, chemical composition and minerals in freeze-dried camu-camu (Myrciaria dubia) (HBK) Mc Vaugh) pulp. Food Nutr Sci. 2015;6(10):869-873.

21. Neves LC, da Silva VX, Pontis JA, Flach A, Roberto SR. Bioactive compounds and antioxidant activity in pre-harvest camu-camu [Myrciaria dubia (HBK) Mc Vaugh]. Fruits Sci Hortic. 2015;186:223-229.

22. Kaneshima T, Myoda T, Nakata M, Fujimori T, Toeda K, Nishizawa M. Rhodomyrtone, an antimicrobial acylphloroglucinol, in the peel of Myrciaria dubia (Camucamu). Food Preserv Sci. 2015;41:71-76.

23. Kaneshima T, Myoda T, Toeda K, Fujimori T, Nishizawa M. Antimicrobial constituents of peel and seeds of camu-camu (Myrciaria dubia). Biosci Biotechnol Biochem. 2017 Aug;81(8):1461-1465.

24. De Azevedo JCS, Fujita A, De Oliveira EL, Genovese MI, Pinto-Correia RT. Dried camu-camu (Myrciaria dubia H.B.K. McVaugh) industrial residue: A bioactive-rich Amazonian powder with functional attributes. Food Res Int. 2014;62:934-940.

25. Nakata HM, Perfecto DR, Cadillo EM, Alvarado EC, Espinoza F. Efectividad in vitro e in vivo de un colutorio a base de Myrciaria dubia "camu camu" sobre bacterias de importancia oral. Theorema, (Lima, Segunda época, En línea). 2016 Jun;(1)1:83-92.

26. Camere-Colarossi R, Ulloa-Urizar G, Medina-Flores D, Caballero-García S, Mayta-Tovalino F, del Valle-Mendoza J. Antibacterial activity of Myrciaria dubia (Camu-camu) against $S$. mutans and S. sanguinis. Asian Pac J Trop Biomed. 2016;6(9):740-744

27. Saldarriaga-Mostacero EG. Efecto antibacteriano in vitro del extracto etanólico de Myrciaria dubia (camu camu) sobre Streptococcus mutans (ATCC 25175). [Tesis]. Trujillo, Perú: Universidad Nacional de Trujillo, Facultad de Odontología; 2017.

28. López-Mata AE. Efecto antibacteriano del zumo de Myrciaria dubia, Citrus grandis y Citrus reticula sobre Escherichia coli y Salmonella tiphy. CIENTIFI-K. 2017:5(1):87-92.

29. García-Sánchez JE, García-Sánchez E, García-García MI. Antimicrobial susceptibility testing of anaerobic bacteria. Enferm Infecc Microbiol Clinic. 2014;32(suppl 1):23-29.

30. Clinical and Laboratory Standards Institute. M02QG Disk diffusion Reading guide. CLSI. 2018;38(4):1-2. 